\title{
First line dual therapy for gonorrhoea to limit the spread of antimicrobial resistance
}

Hamish Mohammed (Principal Surveillance Scientist), Bersabeh Sile (Senior Surveillance Scientist), Martina Furegato (Senior Surveillance Scientist), Sarah Woodhall (Principal Surveillance Scientist), Helen Fifer (Consultant Microbiologist) and Gwenda Hughes (Consultant Epidemiologist and Head of STI Surveillance)

HIV \& STI Department, National Infection Service, Public Health England 61 Colindale Avenue, London NW9 5EQ

There is an outbreak of Neisseria gonorrhoeae with high-level resistance to azithromycin in England. ${ }^{1}$ Since publication of this news article in the BMJ in April 2016, ${ }^{2}$ an additional 22 cases have been identified, with a total of 56 confirmed cases by October $2016 .^{3}$

Most gonorrhoea diagnoses in England are made in specialist sexual health clinics (SHCs), but around $5 \%$ are made in general practice (GP). ${ }^{4}$ The national treatment guideline recommends dual therapy of $500 \mathrm{mg}$ ceftriaxone (intramuscularly) and $1 \mathrm{~g}$ azithromycin (orally) as first-line, to help extend the useful life of cephalosporins. ${ }^{5}$ While over $90 \%$ of cases treated at SHCs receive the recommended first-line therapy, ${ }^{3,5}$ only $9 \%$ of cases treated by GPs between 2011 and 2014 did so. ${ }^{4}$

The national guideline allows for azithromycin monotherapy as an alternative regimen where it is difficult to provide an intramuscular injection (for ceftriaxone); ${ }^{5}$ from 2011 to $2014,19 \%$ of cases treated by GPs received azithromycin monotherapy, but at $1 \mathrm{~g}$, rather than the recommended $2 \mathrm{~g}$ dose.

In the context of increasing resistance to azithromycin, the use of azithromycin monotherapy to treat gonorrhoea, especially with a suboptimal dosage, increases both the likelihood of treatment failure and the selection pressure for the development of ceftriaxone resistance.

GPs are encouraged to refer cases of gonorrhoea to SHCs but should treat patients deemed likely to be lost to follow-up. ${ }^{6}$ However, to limit the spread of antimicrobial resistance and ensure gonorrhoea remains a treatable infection, use of first-line therapy in all settings is strongly recommended.

Word count: 250 (limit: 250) 


\section{References}

1. Chisholm SA, Wilson J, Alexander S, et al. An outbreak of high-level azithromycin resistant Neisseria gonorrhoeae in England. Sexually Transmitted Infections 2015.

2. Wise J. Antibiotic resistant gonorrhoea increases in England. BMJ 2016;353.

3. Public Health England. Surveillance of antimicrobial resistance in Neisseria gonorrhoeae:

Key findings from the Gonococcal Resistance to Antimicrobials Surveillance Programme (GRASP) - Data up to October 2016. Available at:

https://www.gov.uk/government/publications/gonococcal-resistance-to-antimicrobialssurveillance-programme-grasp-report. Accessed 25 Jan, 2017.

4. Mohammed $\mathrm{H}$, Sile B, Furegato $M$, et al. Poor adherence to gonorrhoea treatment guidelines in general practice in England. British Journal of General Practice 2016;66(648):352-52.

5. Bignell C, Fitzgerald M, others. UK national guideline for the management of gonorrhoea in adults, 2011. International journal of STD \& AIDS 2011;22(10):541-47.

6. Royal College of General Practitioners (Sex; Drugs; HIV and Viral Hepatitis Group), British Association for Sexual Health and HIV. Sexually Transmitted Infections in Primary Care 2013 (RCGP/BASHH). Lazaro N. Available at: http://www.rcgp.org.uk/clinicaland-research/clinical-resources/sexually-transmitted-infections-in-primary-care.aspx. Accessed 25 Jan, 2017. 